\title{
Characterization, high-resolution mapping and differential expression of three homologous $P A L$ genes in Coffea canephora Pierre (Rubiaceae)
}

\author{
Maud Lepelley • Venkataramaiah Mahesh · James McCarthy • Michel Rigoreau • \\ Dominique Crouzillat • Nathalie Chabrillange • Alexandre de Kochko • \\ Claudine Campa
}

Received: 14 November 2011 / Accepted: 8 February 2012/Published online: 21 February 2012

(C) The Author(s) 2012. This article is published with open access at Springerlink.com

\begin{abstract}
Phenylalanine ammonia lyase (PAL) is the first entry enzyme of the phenylpropanoid pathway producing phenolics, widespread constituents of plant foods and beverages, including chlorogenic acids, polyphenols found at remarkably high levels in the coffee bean and long recognized as powerful antioxidants. To date, whereas PAL is generally encoded by a small gene family, only one gene has been characterized in Coffea canephora (CcPAL1), an economically important species of cultivated coffee. In this study, a molecular- and bioinformatic-based search for CCPAL1 paralogues resulted successfully in identifying two additional genes, $C C P A L 2$ and $C C P A L 3$, presenting similar genomic structures and encoding proteins with close sequences. Genetic mapping helped position each gene in three different coffee linkage groups, CcPAL2 in particular, located in a coffee genome linkage group (F) which is syntenic to a region of Tomato Chromosome 9 containing a $P A L$ gene. These results, combined with a phylogenetic study, strongly suggest that $C c P A L 2$ may be the ancestral gene of $C$. canephora. A quantitative gene
\end{abstract}

Electronic supplementary material The online version of this article (doi:10.1007/s00425-012-1613-2) contains supplementary material, which is available to authorized users.

M. Lepelley $(\bowtie) \cdot J$. McCarthy · M. Rigoreau · D. Crouzillat Nestlé R\&D Center, 101 Av. Gustave Eiffel, Notre Dame D’Oé, BP 49716, 37097 Tours, France

e-mail: maud.lepelley@rdto.nestle.com

V. Mahesh $\cdot$ N. Chabrillange $\cdot$ A. de Kochko - C. Campa IRD, UMR DIADE (IRD/UM2), BP 64501, 34394 Montpellier, France

V. Mahesh

Avesthagen Limited, International Technology Park,

Whitefield Road, Bangalore 560066, India expression analysis was also conducted in coffee tissues, showing that all genes are transcriptionally active, but they present distinct expression levels and patterns. We discovered that $C c P A L 2$ transcripts appeared predominantly in flower, fruit pericarp and vegetative/lignifying tissues like roots and branches, whereas $C c P A L 1$ and $C C P A L 3$ were highly expressed in immature fruit. This is the first comprehensive study dedicated to $P A L$ gene family characterization in coffee, allowing us to advance functional studies which are indispensable to learning to decipher what role this family plays in channeling the metabolism of coffee phenylpropanoids.

Keywords Chlorogenic acids - Coffea . Gene expression · Gene structure · Mapping · Phenylalanine ammonia lyase
Abbreviations
CGA Chlorogenic acids
COS Conserved ortholog set
EST Expressed sequence tag
HQT Hydroxycinnamoyl-CoA quinate
HRM High-resolution melting
MAS Marker-assisted selection
PAL Phenylalanine ammonia lyase
QTL Quantitative trait loci
q-RT-PCR Quantitative real-time polymerase chain reaction

\section{Introduction}

Over the last few years, an increasing number of studies have focused on the relationship between plant-derived 
foods containing phenolic compounds (flavonoids/hydroxycinnamic acids and esters) with high antioxidant activity and human health (Lila 2007; Ververidis et al. 2007; Han and Baik 2008; Cuevas-Rodriguez et al. 2010). The growing recognition of the importance of plant antioxidants in human health has thus led to increased research interest in the synthesis and accumulation of these antioxidant compounds in plants (Tamagnone et al. 1998; Hoffmann et al. 2004; Niggeweg et al. 2004; Abdulrazzak et al. 2006; Luo et al. 2008; Vallverdu-Queralt et al. 2011). Both academic and applied interest in this area is further stimulated by the fact that some widely consumed plants are relatively rich in flavonoid/phenolic compounds and by the observation that people who consume higher quantities of these foods appear to have lower risks for certain health problems, such as cardiovascular disease and cancer (Sawa et al. 1999; Bazzano et al. 2002; Clifford 2004; Cos et al. 2005; Go et al. 2005).

The early steps of the phenylpropanoid pathway of plants leading to synthesis of flavonoids and hydroxycinnamic acids and esters, including the large family of chlorogenic acids isomers (CGA), have been described in several plants (Dixon and Paiva 1995; Winkel-Shirley 2002; Clé et al. 2008; Vogt 2010). The first step in the phenylpropanoid pathway is the deamination of phenylalanine to cinnamic acid by L-phenylalanine ammonia lyase (PAL, EC 4.3.1.24). PAL is a tetrameric enzyme whose subunits are encoded by a small multigene family in most species that have been studied (Cramer et al. 1989; Wanner et al. 1995; Fukasawa-Akada et al. 1996; Rasmussen and Dixon 1999). The expression of $P A L$ genes are known to be influenced significantly by biotic and abiotic stress (Tovar et al. 2002) and can also be induced during the late plant defense response to pathogens in order to reinforce lignin synthesis in the affected area (Reimers and Leach 1991; Schovankova and Opatova 2011). Four different $P A L$ genes have been characterized in Arabidopsis and these appear to fall into two different groups (Raes et al. 2003; Cochrane et al. 2004; Huang et al. 2010). As expected for a major branch point between primary and secondary plant metabolic pathways, the expression of the different Arabidopsis genes are under complex regulatory control. Three of them (AtPAL1, AtPAL2 and AtPAL4) have been shown to be associated with tissue-specific lignin synthesis (Raes et al. 2003; Rohde et al. 2004) and AtPAL1 and AtPAL2 appear to be more closely associated with environmental stress-induced flavonoid synthesis (Olsen et al. 2008). PAL genes from trees such as poplar have also been studied (Subramaniam et al. 1993; Osakabe et al. 1995; Kao et al. 2002). For example, Kao et al. (2002) reported on the tissue-specific expression of two $P A L$ genes from Populus tremuloides. PtPALl was found to be more substantially expressed in non-lignifying cells exhibiting accumulation of condensed tannins, and thus more closely connected with their biosynthesis and other phenolics, even if it was also found in developing phloem or xylem. However, PtPAL2, expressed in heavily lignified structural cells of shoots, was mostly associated with lignin biosynthesis. Such results strongly suggest that specific $P A L$ genes may have distinct and overlapping functions in the phenylpropanoid pathway. Soon after the PAL enzymatic reaction, the phenylpropanoid metabolites generally enter either the flavonoid or lignin synthesis pathways. This step presumably leads to competition for precursors, more especially for coumaroyl-CoA (Mahesh et al. 2006a; Besseau et al. 2007; Clé et al. 2008).

There is currently little published information on the presence of flavonoids in the green or roasted coffee bean and whether these molecules or derivatives thereof contribute to coffee flavor. However, one report suggests that flavonoids are present in roasted coffee (Yen et al. 2005). Whereas other coffee metabolic pathways like those related to caffeine and sucrose have been thoroughly researched (Ky et al. 2001; Privat et al. 2008), there is a lack of information on the phenylpropanoid diversity in coffee. Actually, the main CGA isomers found in the coffee bean are the only compounds synthesized through this pathway whose levels and diversity are well documented in coffee. Based on research literature, these main CGA are represented by 9 out of a total of 30 different isomers identified by Clifford et al. (2006) in the green bean. These main CGA consist of esters formed between one or two transcinnamic acids (caffeic or ferulic acid) and quinic acid (Clifford 2000), and belong to three classes, each containing three isomers differing in the position of their acyl residues. They include the monocaffeoylquinic acids (CQA; 3CQA, 4CQA and 5CQA), the dicaffeoylquinic acids (diCQA; 3,4diCQA, 3,5diCQA and 4,5diCQA) and the feruloylquinic acids (FQA; 3FQA, 4FQA and 5FQA). Many publications are related to the levels of the main CGA present in green coffee beans, with the corresponding total content found to vary from 7 to $14.4 \%$ dry matter in Coffea canephora (Ky et al. 1999, 2001; Bertrand et al. 2003; Lepelley et al. 2007; Koshiro et al. 2007) and from 3.4 to $4.8 \%$ in C. arabica (Ky et al. 2001). These data illustrate the fact that the CGA quantitative diversity is higher in $C$. canephora than in C. arabica, whereas no qualitative differences were observed between these two species for this type of compound (Ky et al. 2001).

Due to high amounts of the CGA in coffee beans and thus in the coffee beverage, and to the growing list of health benefits potentially associated with CGA, it is of interest to learn more about how their synthesis/accumulation is controlled on a genetic level. Several authors (Campa et al. 2003; Mahesh et al. 2006a; Lepelley et al. 2007; Koshiro et al. 2007; Joët et al. 2009) have already 
characterized key genes involved in CGA metabolism in coffee plants, and/or their transcriptional abundance in several tissues. In contrast, there is currently only limited information concerning critical upstream genes like $P A L$, which are essential for regulating the synthesis of CGA precursors. A recent study by Mahesh et al. (2006b) is, to our knowledge, the only report describing a coffee $P A L$ gene. In that study, the authors isolated and mapped a C. canephora PAL gene (CCPAL1) and presented evidence of its role in accumulating certain CGA in C. canephora, the caffeoylquinic acids. Here, we describe the isolation of two other $C$. canephora PAL cDNA sequences and their corresponding genomic sequences (CCPAL2 and CCPAL3). Comparison of 98 PAL amino acid sequences from 71 plants has allowed us to build a phylogenetic tree which gives a better view on the relationships existing between the three $C$. canephora proteins and related homologs of other plants, including five proteins from $P$. trichocarpa (Shi et al. 2010a, b), a woody plant whose genome was sequenced and annotated by Tuskan et al. (2006). In addition, we have mapped the three genes on a $C$. canephora consensus map (LefebvrePautigny et al. 2010) and have presented the comparative expression of all three coffee $P A L$ genes in different plant organs and tissues at different growth stages to better understand the potential impact of each gene on the synthesis of chlorogenic acids, flavonoids and downstream products such as lignin in coffee.

\section{Materials and methods}

\section{Plant material}

Young leaves of the $C$. canephora BP409 clone were harvested from trees grown in the greenhouse $\left(25^{\circ} \mathrm{C}\right.$ and $70 \%$ relative humidity) at Nestlé R\&D facilities in Tours, France, and kept at $-80^{\circ} \mathrm{C}$ before use. C. canephora (BP409, 2001) cherries, branches, roots and flowers were harvested from trees cultivated on the experimental farm of ICCRI (Indonesia). The samples were frozen immediately in liquid nitrogen and then sent packed in dry ice to the Nestle R\&D Center in Tours, France.

The cherry developmental stages are defined as follows: small green fruit (SG), large green fruit (LG), yellow fruit (Y) and red fruit (R). More details on these stages can be found in Privat et al. (2008). The bean and pericarp tissues of the frozen cherries were rapidly separated for each stage of maturation and then homogenized using a SPEX CertiPrep 6800 Freezer Mill with liquid nitrogen. The powders obtained were then used for RNA extraction.
RNA preparation and cDNA synthesis for q-RT-PCR experiments

The total RNA was extracted from powdered samples by using a phenol-/chloroform-based method as described previously (Rogers et al. 1999) and treated with DNase to remove DNA contamination as described by Lepelley et al. (2007). Using $1 \mu \mathrm{g}$ of total RNA and $270 \mathrm{ng}$ poly $\mathrm{dT}(18)$ (Eurogentec, Seraing, Belgium) as primers, the method used to make the cDNA was identical to the protocol described in the Superscript II Reverse Transcriptase kit (Invitrogen, Carlsbad, CA, USA) except that the enzyme used was not Superscript II but Superscript III and that the first-strand cDNA-synthesis incubation step was performed for $50 \mathrm{~min}$ at $50^{\circ} \mathrm{C}$, and not $42^{\circ} \mathrm{C}$. The cDNA samples generated were then diluted 100 -fold in sterilized water and stored at $-20^{\circ} \mathrm{C}$ for later use in quantitative real-time PCR (q-RT-PCR).

\section{Quantitative real-time PCR (q-RT-PCR) experiments}

Using the cDNA synthesized as described above, quantitative PCR with TaqMan probes and primers was carried out as described previously by Simkin et al. (2006), except that the cDNA dilutions and the Taqman primers/probes were different. The TaqMan ${ }^{\circledR}$ probe-based chemistry uses a fluorogenic probe to enable the detection of a specific PCR product as it accumulates during PCR. The primers and TaqMan probes used were designed with the Primer Express software (Applied Biosystems, Foster City, CA, USA) and are listed in Supplementary Table S1. Each primers/probe set was designed to be specific to the target gene to avoid the amplification of other related genes. Moreover, the last five bases on the $3^{\prime}$ end of the primers were designed to contain no more than two $\mathrm{C}$ and/or $\mathrm{G}$ bases, which is another factor that prevents the possibility of non-specific PCR product formation. The amplification efficiency of the primer/probe sets was tested on various dilutions of the corresponding plasmids and were all found to be near $100 \%$. Quantification was conducted using the GeneAmp 7500 Sequence Detection System (Applied Biosystems) and repeated three times for each reaction. Transcript levels were normalized to the levels of the constitutively expressed ribosomal rpl39 gene.

Primer design and PCR amplification for cDNA isolation

Primer design was performed based on $C$. canephora cDNA sequences available in the EST databases developed in the IRD laboratory (Poncet et al. 2006). For CcPAL2, a reverse primer $P A L B R$ (5'-GGACAAGATCACCTGATGCAGT $-3^{\prime}$ ) was designed to amplify the $5^{\prime}$ end. PCRs were 
carried out using GoTaq DNA polymerase (Promega, Madison, WI, USA) following the manufacturer's recommendations. Both cDNA libraries (derived from fruit or from leaf) were used as matrices for a PCR reaction using a combination of the PALBR gene-specific primer and the universal T3 vector-specific primer. PCR cycles were as follows: $5 \mathrm{~min}$ at $94^{\circ} \mathrm{C}$, followed by 30 cycles of $50 \mathrm{~s}$ at $94^{\circ} \mathrm{C}, 50 \mathrm{~s}$ at $52^{\circ} \mathrm{C}$, and $50 \mathrm{~s}$ at $72^{\circ} \mathrm{C}$, and then $10 \mathrm{~min}$ at $72^{\circ} \mathrm{C}$.

For $C C P A L 3$, a reverse primer PALCR2 (5'-GCGACTT GGTGAACTGTGCTCTTG- $3^{\prime}$ ) was designed to amplify the $5^{\prime}$ end. As for $C C P A L 2$ isolation, PCR reactions were run as described above on both cDNA libraries using the combination of the reverse primer PALCR2 and a vectorspecific T3 primer, under the following conditions: $5 \mathrm{~min}$ at $94^{\circ} \mathrm{C}$, followed by 30 cycles of $50 \mathrm{~s}$ at $94^{\circ} \mathrm{C}, 50 \mathrm{~s}$ at $52^{\circ} \mathrm{C}$, and $50 \mathrm{~s}$ at $72^{\circ} \mathrm{C}$, and then $10 \mathrm{~min}$ at $72^{\circ} \mathrm{C}$.

Primer design and PCR amplification for gene structure

To define the position, length and sequence of $P A L$ introns, C. canephora genomic DNA $(\sim 100 \mathrm{ng})$ was extracted from leaves of trees maintained in tropical greenhouses at IRD Montpellier using the DNeasy Plant Mini-Kit (Qiagen, Hilden, Germany). Primers were designed in the first exon for the forward primer and in the second exon for the reverse one, closer to the intron, assuming that all the $C$. canephora $P A L$ genes have their intron at the same position, the reference being $C C P A L 1$ (Mahesh et al. 2006b). For $C C P A L 2$, the primers $P A L B F 1$ (5'-GGTGCCCTTCAG AAGGAGCTTATT- $\left.3^{\prime}\right)$ and PALBR (5'-GGACAAGATCA CCTGATGCAGT- $3^{\prime}$ ) were used in presence of GoTaq (Promega). PCR conditions were: $5 \mathrm{~min}$ at $94^{\circ} \mathrm{C}$, followed by 29 cycles of $40 \mathrm{~s}$ at $94^{\circ} \mathrm{C}, 50 \mathrm{~s}$ at $52^{\circ} \mathrm{C}$ and $1 \mathrm{~min}$ at $72^{\circ} \mathrm{C}$, and then $10 \mathrm{~min}$ at $72^{\circ} \mathrm{C}$. The forward primers $P A L I F$ (5'-GTTACGGTATCACCACCGGCTTTG) and PALDF1 (5'-CATTCCAATCGCTTCTGCGTCC-3') and the reverse primers PALR2 ( $5^{\prime}$-TAGAAGCCCTTGTTGC CGAGTGAG) and PALDRI (5'-CGTGTGACCTGACTC TGTTCCAT-3') were used for $C c P A L 1$ and $C C P A L 3$, respectively, and the PCR conditions were: $5 \mathrm{~min}$ at $94^{\circ} \mathrm{C}$, followed by 29 cycles of $40 \mathrm{~s}$ at $94^{\circ} \mathrm{C}, 50 \mathrm{~s}$ at $52^{\circ} \mathrm{C}$ and $1 \mathrm{~min}$ at $72^{\circ} \mathrm{C}$, and then $10 \mathrm{~min}$ at $72^{\circ} \mathrm{C}$.

Subcloning and sequencing

The PCR products were checked on $1 \%(\mathrm{w} / \mathrm{v})$ agarose gels after ethidium bromide staining and directly purified (QIAquick PCR Purification Kit, Qiagen) for sequencing (MWG-Biotech/Eurofins; Nantes, France) or cloned into a TOPO-TA vector (Invitrogen) and transformed into One Shot $\odot$ TOP10 competent cells. Plasmid DNA was isolated from overnight cultures using the QIAprep Spin Miniprep protocol (Qiagen) and sequenced.

Phylogenetic analysis

The amino acid sequences of PALs from fungi, gymnosperms and angiosperms were searched in public databases available at NCBI (http://www.ncbi.nlm.nih.gov). Only full amino acid sequences were used (length of about $700 \mathrm{AA}$ ), with a preference for species in which more than one gene was described. Phylogenetic analysis was conducted using Geneious software (5.5.5 version; Biomatters Ltd, Auckland, New Zealand) and the neighbor-joining method was used to build the phylogenetic tree (Drummond et al. 2011). Bootstrap analysis was performed using 1,000 replicates. The accession numbers and the sequences names, as used in Fig. 2, are also reported in Supplementary Table S2 which also contains the full name of the species from which the sequences were isolated.

\section{Coffee genetic mapping}

Using high-resolution melting (HRM) technology, $C c P A L 1, C c P A L 2$ and $C c P A L 3$ genes were mapped on the C. canephora COSII (Conserved Ortholog Set) genetic map $(\mathrm{BP} 409 \times$ Q121) published by Lefebvre-Pautigny et al. (2010). Primer pairs were designed for each $P A L$ sequence to obtain an amplified DNA fragment length between 200 and 350 bp: PAL1-HRM-FP (GGGAGAGT TGGGGACCAAT) and PAL1-HRM-RP (TTCAACATTT ATGGCAACGAAC) as the forward and reverse primers for amplifying a 321-bp DNA fragment specific to $C C P A L 1$ gene; PAL2-HRM-FP (ACTGCTGACTGGAGAGAAAG) and PAL2-HRM-RP (TGGGTGTTACAGACATATCA) as the forward and reverse primers for amplifying a 228-bp DNA fragment specific to $C c P A L 2$; and finally PAL3HRM-FP (AGAGCTGAAGACCCTTTTGC) and PAL3HRM-RP (CTCTTCTGTCGGCCTTCAC) as the forward and reverse primers for amplifying a 344-bp DNA fragment specific to CCPAL3.

As described for the HRM assays referred to by Lefebvre-Pautigny et al. (2010), the reagent components for one genotyping assay were added to the $20-\mu$ final reaction volume as follows: $2 \mu \mathrm{l}$ of genomic DNA (20 ng), $10 \mu \mathrm{l}$ of Master Mix ( $2 \times$ containing fluorescent dye), $1 \mu$ l of primer mix (final concentration of $0.2 \mu \mathrm{M}$ for each primer), $2.4 \mu \mathrm{l}$ of $\mathrm{MgCl}_{2}$ and $3.6 \mu \mathrm{l}$ of sterilized water. Then, PCR reactions were run using the Lightcycler ${ }^{\circledR} 480$ Thermocycler (Roche). The PCR conditions were as follows: $10 \mathrm{~min}$ at $95^{\circ} \mathrm{C}$, followed by 45 cycles of $10 \mathrm{~s}$ at $95^{\circ} \mathrm{C}, 15 \mathrm{~s}$ at $60^{\circ} \mathrm{C}$ and $25 \mathrm{~s}$ at $72^{\circ} \mathrm{C}$ then followed by a last denaturing step of $1 \mathrm{~min}$ at $95^{\circ} \mathrm{C}, 1 \mathrm{~min}$ at $40^{\circ} \mathrm{C}$ (renaturation), and finally 
ending with a ramp rate of $0.02^{\circ} \mathrm{C} / \mathrm{s}$ from 60 to $95^{\circ} \mathrm{C}$ (melting). During this last step, fluorescence is read 25 times per degree. Analyses of DNA melting curves and allele segregations were performed using "Gene Scanning" software (Roche).

\section{Bioinformatic analysis}

Determination of percentage identities shared between CcPAL1, CcPAL2 and CcPAL3 protein sequences and their closely related sequences in several plant species.

Using NCBI as the worksite, each of the three coffee PAL protein sequences discussed here was used as a query of a BLASTP search against NCBI non-redundant databases, using the default alignment parameters. Several of the best hits found were selected and reported in Table 1. The percentage of identity (PIs) shared between the protein sequences of these hits along with the respective coffee PAL protein sequences, the alignment scores and the $e$ values resulting from these alignments are also shown in Table 1.

\section{Genbank accession numbers}

Sequence data from this article have been deposited into GenBank under the following accession numbers: C. canephora CcPAL1 cDNA (AF460203), C. canephora CcPAL2 cDNA (JF805760) and C. canephora CcPAL3 cDNA (JF805761); C. canephora CcPAL1 protein (AAN32866), C. canephora CcPAL2 protein (AEO94540) and $C$. canephora CcPAL3 protein (AEO94541); C. canephora CcPAL1 genomic DNA (JN420343), C. canephora CcPAL2 genomic DNA (JN420344) and C. canephora CcPAL3 genomic DNA (JN420345). Note that, as additional information, $C$. arabica CaPAL1 and CaPAL2 cDNA sequences were also deposited under accession numbers JF838179 and JF838180, respectively.

\section{Results}

Isolation and characterization of $P A L$ homologous genes in $C$. canephora

Screening both partial $C$. canephora EST databases developed at IRD (Poncet et al. 2006) allowed us to identify two partial cDNA sequences ( $C C P A L B$ and $C c P$ $A L D)$ encoding putative phenylalanine ammonia lyase (PAL). These sequences differed from that of $C c P A L 1$, but were truncated at the $5^{\prime}$ end. Reverse PCR performed on both leaf and fruit cDNA libraries helped to amplify several fragments. The longest cDNA sequences were found to represent two new full-length cDNA clones which were called $C C P A L 2$ and $C C P A L 3$.

Analysis of the open reading frames of the new cDNAs showed that both sequences were slightly shorter than that of $C C P A L 1$, with $C C P A L 2$ and $C C P A L 3$ being 2,136-bp and 2,142-bp long, respectively (vs. 2,154 bp for CcPAL1). They encoded polypeptides of 711 and 713 amino acids, respectively (717 AA for CcPAL1). The comparison of the three CcPAL amino acid sequences is presented in Supplementary Fig. S1. The predicted molecular mass and theoretical $\mathrm{p} I$ of the two new coffee PALs proteins (77.2 $\mathrm{kDa}$ and $6.14 ; 77.7 \mathrm{kDa}$ and 6.54 , respectively) are consistent with the size determined for PAL polypeptides from other plants which vary from 72 to $83 \mathrm{kDa}$ (reviewed in Hahlbrock and Grisebach 1979). The predicted AA sequences showed the expected conserved patterns found in all other PAL sequences, in particular those at the PAL active site: G-[STG]-[LIVM]-[STG]-[AC]-S-G-[DH]-LX-P-L-[SA]-x(2)-[SAV] (Schuster and Rétey 1994). By using parsley PAL as a model, Schuster and Rétey (1994) predicted that the active site was associated with a serine residue that had been converted to dehydroalanine. This serine residue is conserved among the species and is located at the following positions from the first methionine: 204 in CcPAL1, 198 in CcPAL2 and 201 in CcPAL3. The deduced amino acid sequences of CcPAL1 and CcPAL2 shared $83 \%$ identity. There is $83 \%$ identity between PAL1 and PAL3 and $82 \%$ identity between PAL2 and PAL3 (Table 1). As noted in other PAL protein sequences, the maximum divergence was found at the $\mathrm{N}$-terminal extremities.

Analyzing the corresponding genomic clones revealed that, as expected and similarly to $C c P A L 1$, both $C c P A L 2$ and $C C P A L 3$ contained only one intron. This intron was positioned at 404, 386 and 395 bases from the ATG for CCPAL1, CCPAL2 and CCPAL3, respectively. Its length varied from 1,263 bp for CcPAL2 to 1,338 bp for CcPAL3 and 1,903 bp for CcPAL1 (Fig. 1). Curiously, CcPAL1 had a phase 2 intron, the rarest in eukaryotes (Fedorov et al. 1992), and both CCPAL2 and CCPAL3 have a phase 1 intron. In genomic $P A L$ sequences of other plants, a single intron was also observed, its length varying from $90 \mathrm{bp}$ in Pisum sativum (Yamada et al. 1992) to 1,900 bp in Nicotiana tabacum. In angiosperms, similarly to the three genes from $C$. canephora already observed, this intron is generally positioned between the second and third bases of a conserved Arg codon. The cDNA sequences showed that the exon-intron junctions in the $C c P A L$ genes maintained the "GT-AG" rule for donor/acceptor sites (Breathnach and Chambon 1981). The first exon varied in length, encoding $135 \mathrm{AA}, 129 \mathrm{AA}$ or $132 \mathrm{AA}$ in CcPAL1, CCPAL2 and CCPAL3, respectively. The length of Exon 2 
Table 1 Amino acid sequence identities shared between CcPAL1 (accession number \#AAN32866), CcPAL2 (accession number \#AEO94540) and CcPAL3 (accession number \#AEO94541) protein sequences and some of their best hits found, plus Arabidopsis thaliana PAL hits-from a BLASTP search using the coffee sequences as queries against the non-redundant database of NCBI

\begin{tabular}{|c|c|c|c|c|c|}
\hline Species & Sequence & Sequence accession number & Identity $(\%)$ & $e$ value & Score (bits) \\
\hline \multicolumn{6}{|c|}{ Coffea canephora CcPAL1 hits (CcPAL1 accession number \#AAN32866) } \\
\hline Populus trichocarpa & PtrPAL5 & ACC63889 & 87 & 0.0 & 1264 \\
\hline Manihot esculenta & MePAL1 & AAK62030 & 86 & 0.0 & 1258 \\
\hline Vitis vinifera & VvPAL & ABM67591 & 85 & 0.0 & 1269 \\
\hline Camellia sinensis & CsPAL & BAA05643 & 84 & 0.0 & 1251 \\
\hline Citrus limon & ClPAL & AAB67733 & 84 & 0.0 & 1254 \\
\hline Manihot esculenta & MePAL2 & AAK60275 & 84 & 0.0 & 1248 \\
\hline Coffea canephora & CcPAL2 & AEO94540 & 83 & 0.0 & 1235 \\
\hline Coffea canephora & CcPAL3 & AEO94541 & 83 & 0.0 & 1200 \\
\hline Arabidopsis thaliana & AtPAL1 & AEC09341 & 82 & 0.0 & 1208 \\
\hline Arabidopsis thaliana & AtPAL4 & AEE74893 & 82 & 0.0 & 1180 \\
\hline Arabidopsis thaliana & AtPAL2 & AEE79055 & 81 & 0.0 & 1213 \\
\hline Arabidopsis thaliana & AtPAL3 & AED90714 & 75 & 0.0 & 1050 \\
\hline \multicolumn{6}{|c|}{ Coffea canephora CcPAL2 hits (CcPAL2 accession number \#AEO94540) } \\
\hline Catharanthus roseus & CrPAL & BAA95629 & 88 & 0.0 & 1312 \\
\hline Ipomoea nil & InPAL & AAG49585 & 88 & 0.0 & 1302 \\
\hline Nicotiana tabacum & NtPAL1 & BAA22948 & 88 & 0.0 & 1300 \\
\hline Nicotiana tabacum & NtPAL2 & BAA22963 & 87 & 0.0 & 1295 \\
\hline Capsicum аппиит & CaPAL & ACF17667 & 88 & 0.0 & 1291 \\
\hline Daucus carota & DcPAL & BAC56977 & 86 & 0.0 & 1291 \\
\hline Arabidopsis thaliana & AtPAL1 & AEC09341 & 83 & 0.0 & 1224 \\
\hline Arabidopsis thaliana & AtPAL2 & AEE79055 & 82 & 0.0 & 1210 \\
\hline Coffea canephora & CcPAL3 & AEO94541 & 82 & 0.0 & 1197 \\
\hline Arabidopsis thaliana & AtPAL4 & AEE74893 & 82 & 0.0 & 1187 \\
\hline Arabidopsis thaliana & AtPAL3 & AED90714 & 73 & 0.0 & 1041 \\
\hline \multicolumn{6}{|c|}{ Coffea canephora CcPAL3 hits (CcPAL3 accession number \#AEO94541) } \\
\hline Camellia oleifera & CoPAL & ACT21093 & 85 & 0.0 & 1255 \\
\hline Populus trichocarpa & PtrPAL2 & ACC63890 & 85 & 0.0 & 1232 \\
\hline Jatropha curcas & JcPAL & ABI33979 & 84 & 0.0 & 1248 \\
\hline Ricinus communis & RcPAL & EEF42935 & 84 & 0.0 & 1243 \\
\hline Vitis vinifera & VvPAL & ABM67581 & 84 & 0.0 & 1234 \\
\hline Manihot esculenta & MePAL1 & AAK62030 & 84 & 0.0 & 1224 \\
\hline Manihot esculenta & MePAL2 & AAK60275 & 83 & 0.0 & 1231 \\
\hline Catharanthus roseus & CrPAL & BAA95629 & 83 & 0.0 & 1226 \\
\hline Pyrus communis & PcPAL & ABB70117 & 82 & 0.0 & 1232 \\
\hline Arabidopsis thaliana & AtPAL2 & AEE79055 & 81 & 0.0 & 1188 \\
\hline Arabidopsis thaliana & AtPAL4 & AEE74893 & 81 & 0.0 & 1178 \\
\hline Arabidopsis thaliana & AtPAL1 & AEC09341 & 79 & 0.0 & 1191 \\
\hline Arabidopsis thaliana & AtPAL3 & AED90714 & 74 & 0.0 & 1042 \\
\hline
\end{tabular}

is conserved in $C C P A L 1$ and $C c P A L 2$ paralogs $(1,750 \mathrm{bp})$ and that of $C c P A L 3$ was remarkably close $(1,747 \mathrm{bp})$.

A high level of identity (over $80 \%$ ) was observed when comparing the deduced amino acid sequence of the three coffee genes with PAL sequences from other plants (Table 1). The highest identity was obtained when comparing C. canephora CcPAL2 with Catharanthus roseus, Ipomea nil, N. tabacum and Capsicum annuum PAL sequences ( $88 \%$ identity). The CcPAL3 protein sequence shared less identity (83\%) with this $C$. roseus PAL amino acid sequence (\#BAA95629). A rooted phylogenetic tree for PAL protein families from several different species was 
Fig. 1 Representation of the structure of the $P A L$ gene family in Coffea canephora. Exons and untranslated regions (UTRs) are shown as boxes and introns are indicated as lines

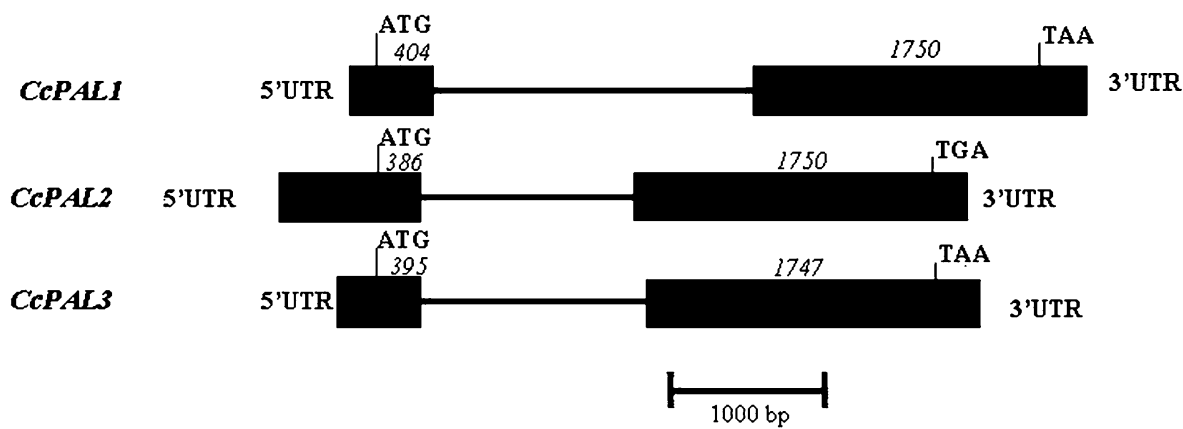

constructed using the three PALs from $C$. canephora and 97 PALs from other plants. A PAL amino acid sequence from the fungus (Rhodothorula glutinis) was used as the root (Fig. 2). CcPAL1 and CcPAL3 sequences were found distant, however, from CcPAL2, which was more closely related to the $C$. roseus PAL sequence discussed above. This plant, like the coffee tree, is a member of the Gentianales, an order of flowering plants which belongs to the Asterid clade (APG II classification). In fact, 34 sequences out of the 39 analyzed belonging to the Asterids are branched together. The same observation can be made for 29 PAL sequences among the 41 analyzed for the Rosids. Only 17 sequences among the 70 from Eudicots and a Basal dicot (Persea americana) are grouped with some monocots. Most of them actually appeared to be PAL sequences deduced from genes that possess homologs in the Rosid or Asterid branches of the tree. For example, P. trichocarpa, Phaseolus vulgaris, Manihot esculenta, Arabidopsis thaliana (Rosids) or Scutellaria baicalensis (Asterids) had PAL sequences close to $C$. canephora's PAL1 and 3, but these species presented other PAL sequences that closely matched the order of the species that they belong to: Fabales, Malpighiales and Brassicales, respectively, for the Rosids; Lamiales for the Asterids. The phylogenetic tree (Fig. 2) also shows that the five PAL proteins from $P$. trichocarpa (PtrPALs) are clustered into two different phylogenetic groups, which is consistent with the results obtained by Shi et al. (2010a, b), who also classified them into two phylogenetic groups, each subset having a tissue-specific expression shared between the members belonging to it: subset A (PtrPAL2, PtrPAL4 and PtrPAL5) and subset B (PtrPAL1 and PtrPAL3). It is interesting that from the tree, the two PtrPALs from subset $\mathrm{B}$ are shown to be very close to other Malpighiales protein sequences and are phylogenetically closer to CcPAL2 than to the other two CcPALs and three PtrPALs proteins, whereas the three PtrPALs from subset A are phylogenetically closer to CcPAL1 and CcPAL3. Protein sequences such as CcPAL2, PtrPAL1 and PtrPAL3 whose phylogenetic relationships are comparable to those given by the phylogenetic classification APGII might therefore correspond to sequences encoded by orthologous genes derived from the same ancestor. The other PAL protein sequences issued from these species (CcPAL1 and CcPAL3 for coffee and PtrPAL2, PtrPAL4 and PtrPAL5 for poplar) may result from gene duplication events leading to paralogous genes, which may have occurred after the divergence from the common ancestor. By observing similar grouping when comparing PtrPAL protein sequences and PtrPAL specific gene expression (Shi et al. 2010a, b), we may deduce that the differences observed in the promoter region and in the coding sequence from a specific subset resulted from the same duplication event. However, the fact that $P$. trichocarpa proteins from the subset B grouped with PAL proteins from plants that are not woody angiosperms, such as Euphorbiaceae, leads us to speculate that the xylem specificity of this subset would probably not be related to the protein sequences, but rather to the promoter sequences.

Tissue-specific expression of $P A L$ genes in C. canephora

The transcript levels of $C C P A L 1, C c P A L 2$ and $C c P A L 3$ were measured in several tissues of the Robusta variety BP409 using q-RT-PCR. The three $P A L$ genes were expressed in nearly all the tissues examined, but the transcript levels showed significant variations depending on the PAL gene and/ or the tissue and organ (Fig. 3). In the bean, the relative expression data for the three $P A L$ genes highlighted that the CCPALI and CCPAL3 genes were highly and similarly expressed at the more immature stage with $\mathrm{RQ}_{\mathrm{PAL} 1(B e a n-}$ $\mathrm{SG})=1.03$ and $\mathrm{RQ}_{\mathrm{PAL} 3(\mathrm{Bean}-\mathrm{SG})}=1.13$, whereas expression of the CCPAL2 gene was nearly 20 times lower at the same stage with $R_{\mathrm{PAL} \text { (Bean-SG) }}=0.045$ ). As bean development progresses, CcPAL3 expression falls to nearly undetectable levels. This observation suggests that the corresponding protein is needed at high levels for bean metabolism at the early stage (small green) and also possibly at the next stage (LG, large green fruit). It will be interesting in the future to determine if this protein is present after this point of development using Western blotting. In contrast to $C C P A L 3, C c P A L 1$ and 


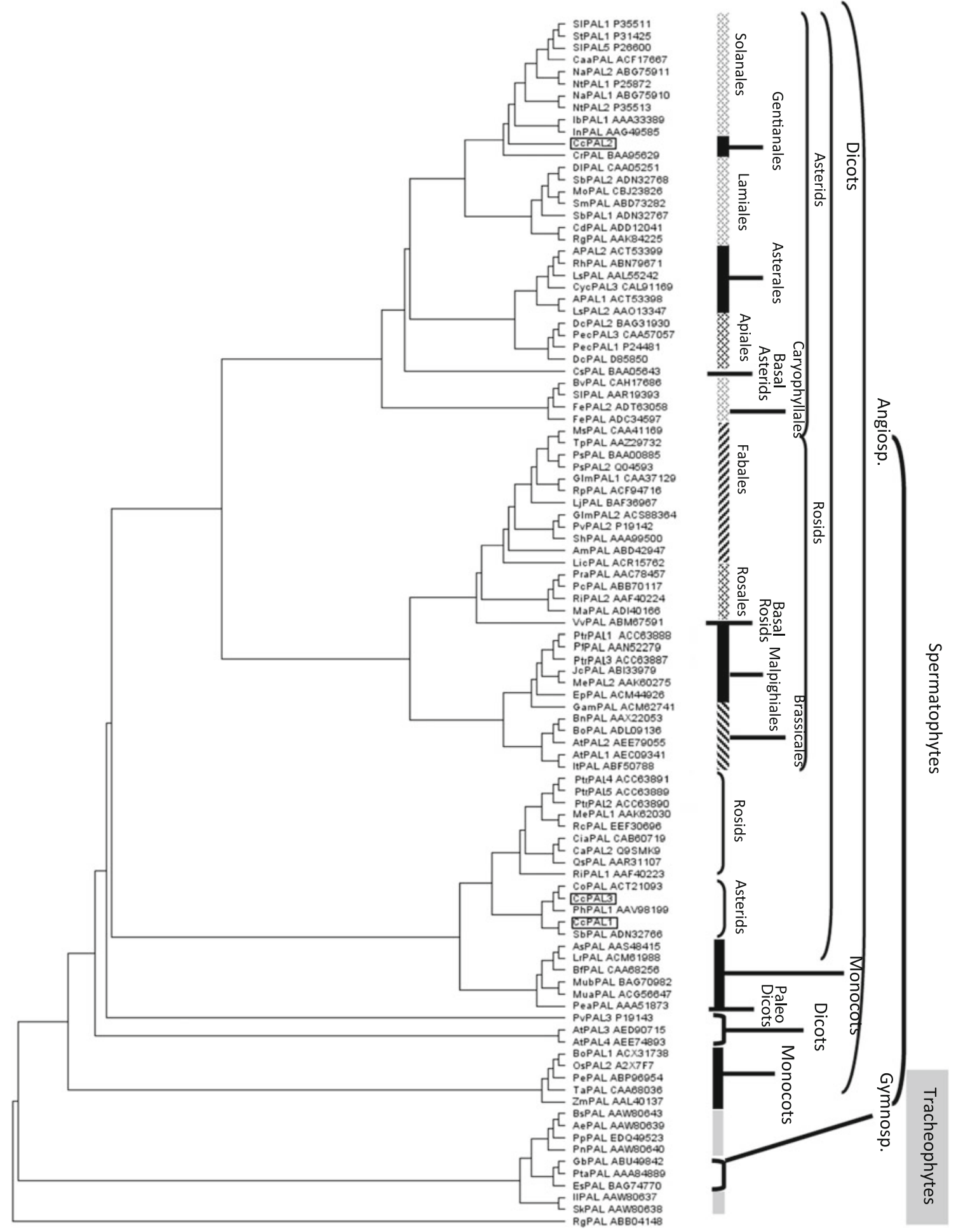

Fig. 2 Phylogenetic relationships between the Coffea canephora PAL proteins and PAL proteins from spermatophytes (dicots, monocots and gymnosperms) and tracheophytes using Rhodotorula glutinis PAL protein sequence as an outgroup (see Supplementary Table S2)

CcPAL2 transcripts are found at reasonable levels in the later stages of bean development, with $C c P A L 1$ and $C c P A L 2$ showing $R Q=0.25$ and $R Q=0.10$, respectively, in the $L G$ stage.
All three PAL genes in the pericarp are expressed at their highest level at the more immature stage $\left(\mathrm{RQ}_{\mathrm{PAL} 1 \text { (Pericarp-SG) }}=0.94, \mathrm{RQ}_{\mathrm{PAL} 2 \text { (Pericarp-SG) }}=0.99\right.$ and $\mathrm{RQ}_{\mathrm{PAL} 3 \text { (Pericarp-SG) }}=0.60$ ). Then, the transcript levels 


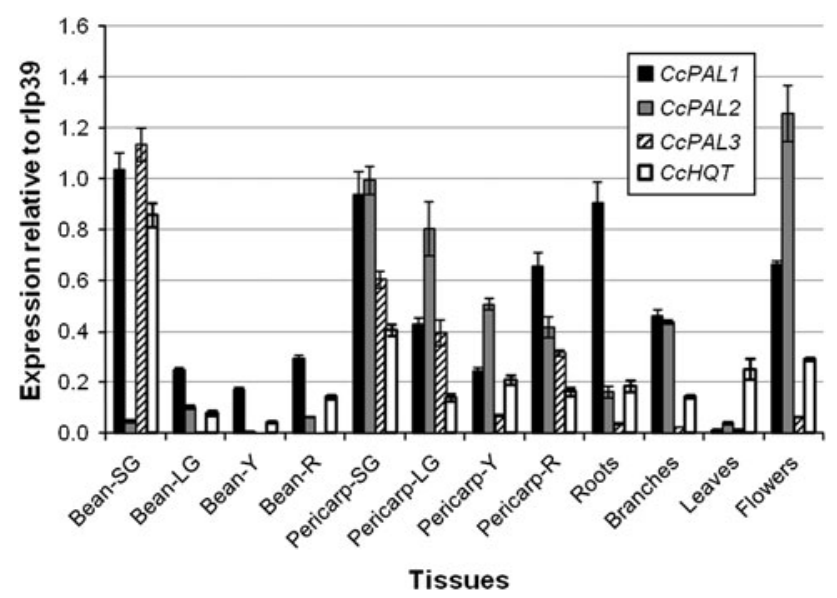

Fig. 3 Relative expression of $C C P A L 1, C c P A L 2, C c P A L 3$, three $P A L$ family members and of $H Q T$ in different tissues and organs of a Coffea canephora variety (Robusta BP409). The gene expression relates to the constitutively expressed gene RPL39. Bean-SG small green-stage bean, Bean- $L G$ large green-stage bean, Bean- $Y$ yellowstage bean, bean- $R$ red-stage bean, Pericarp- $S G$ small green-stage pericarp, Pericarp- $L G$ large green-stage pericarp, Pericarp- $Y$ yellowstage pericarp, Pericarp- $R$ red-stage pericarp

decrease progressively through the next two maturation stages ( $\mathrm{LG}$ and $\mathrm{Y}$ ) and stabilize at the most mature (R) stage for $C c P A L 2$, whereas $C c P A L 1$ and $C c P A L 3$ expressions increase slightly. This latter observation suggests that $C C P A L 1$ and $C c P A L 3$ could play a significant role in the final red fruit/pericarp coloration at the mature stage, a color which is probably due to the synthesis of certain flavonoids/anthocyanins.

Regarding expression in vegetative tissues, relatively low transcript levels were found for all three CcPALs in leaves, but significant levels of $C C P A L 1$ and $C c P A L 2$ transcripts were found in the roots, branches and flowers, with the higher expression found in the flowers being attributed to $C c P A L 2\left(\mathrm{RQ}_{\mathrm{PAL} 2 \text { (Flowers) }}=1.26\right)$, the highest expression found in the roots being attributed to CCPAL1 $\left(\mathrm{RQ}_{\mathrm{PAL1} \text { (Roots) }}=0.9\right)$ and similar transcript levels detected for $C c P A L 1$ and $C c P A L 2$ in the branch $(\mathrm{RQ} \approx 0.45)$. Thus, $C c P A L 1$ and $C C P A L 2$ are likely to make important contributions to vegetative tissue phenylpropanoid metabolism, whereas $C c P A L 3$ appears to have a much smaller role in the bulk of these tissues.

\section{$C c P A L$ map location on a $C$. canephora map}

Using HRM technology, the three $P A L$ genes were mapped on the $C$. canephora COSII genetic map published by Lefebvre-Pautigny et al. (2010). This genetic map includes 396 COSII markers allowing for syntenic studies among plant species. As shown in Fig. 4, each CcPAL gene was mapped in a different linkage group, confirming that at least three distinct $C C P A L$ genes are present in the
C. canephora genome. CcPAL1, CcPAL2 and CCPAL3 are, respectively, located on coffee linkage groups $\mathrm{B}, \mathrm{F}$ and $\mathrm{A}$.

As in another result shown in Fig. 4 and based on Lefebvre-Pautigny et al. (2010), the CCPAL2 gene is the only one of the three coffee $P A L$ genes to be located in a coffee chromosome region that was found to be syntenic to the tomato genome. More precisely, the coffee syntenic genome area carrying $C c P A L 2(3-23 \mathrm{cM})$ on linkage group $\mathrm{F}$ is found to be syntenic with a fragment of the tomato chromosome $9(0.5-24 \mathrm{cM})$. In addition, and thanks to tomato maps available through the SGN Web site hosted at the Boyce Thompson Institute (New York, USA) (http://solgenomics.net/), it was discovered that this tomato chromosome region contains an RFLP-type tomato marker (CT225) that also encodes a PAL protein.

\section{Discussion}

Searching for CCPAL1 paralogs in C. canephora successfully led to the isolation of two new coffee $P A L$ genes, CCPAL2 and CCPAL3, which differed by the encoded proteins and their location on the $C$. canephora genetic map (Lefebvre-Pautigny et al. 2010). In addition, a complementary bioinformatic analysis aimed at establishing the number of $P A L$ genes expressed in the coffee plant was conducted to screen the publicly available $C$. canephora EST databases (Lin et al. 2005; http://solgenomics.net/). This study detected the same three genes, but found no other potential $P A L$ gene. The resulting mapping data obtained for the three genes will be integrated into a study aiming to identify the quantitative trait loci (QTL) affecting agronomically important traits in coffee beans. If these genes are found to co-localize with the identified QTL, they will likely be used as candidates for improving coffee plants through marker-assisted selection (MAS) (Srinivas et al. 2009; Mohan et al. 2010). The presence of these three expressed $P A L$ paralogs in $C$. canephora is consistent with results already obtained for other plant species. Indeed, $P A L$ genes generally belong to a multigene family whose number of genes varies depending on the plant considered. For example, A. thaliana contains four $P A L$ genes: AtPAL1 $\rightarrow$ AtPAL4 (Raes et al. 2003). But some plant species, such as the potato or particularly the tomato, contain several decades of $P A L$ genes among which many are inactive (Joos and Hahlbrock 1992; Chang et al. 2008). It would thus be interesting to determine whether such transcriptionally inactive $P A L$ genes could also exist in coffee, which would not be surprising, given the fact that coffee and tomato share common gene repertories (Lin et al. 2005). The forthcoming genome sequence of $C$. canephora will certainly help answer that question. Nevertheless, even when degenerated primers were used to 
Fig. 4 Genetic mapping of CcPAL1, CcPAL2 and CCPAL3 on the coffee COSII "synteny" map. The letters A, B and F represent coffee linkage groups A, B and F. Shared regions of synteny between coffee and tomato are shown as colored blocks, and were deduced by COSII loci mapping in both species (Lefebvre-Pautigny et al. 2010). Each region sharing synteny with tomato is marked by a different color (modified from Wu et al. 2009). Shared regions of synteny with tomato chromosomes are indicated by: red for chromosome 11, blue for chromosome 9, black for chromosome 3 , green for chromosome 2, pink for chromosome 1 and brown for chromosome 7
A

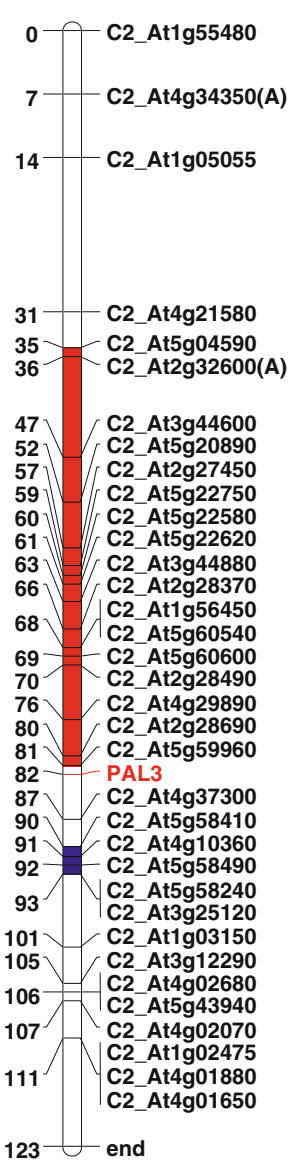

B

0

4

6
7

8

10

13
15

16

2

23

24

3

3

4

5

51

56

58

60

60

66

78

83

87

91
92

93

95

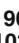

96
103

109
111
117

117

129
130

134

143

145

150
153

153

157

163
165
166

166

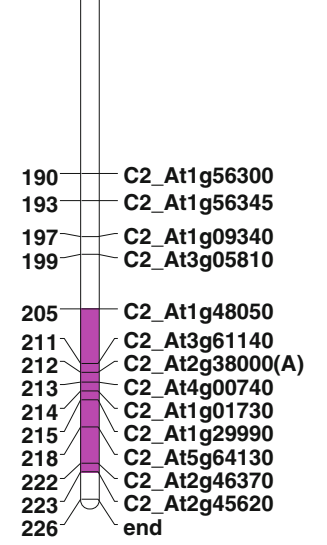

2_At5g53000

C2_At1965000

C2_At3g03070

C2_At3g03100

C2_At5g17560

C2_At5g24170

C2_At4g10810

C2 At3g49260

C2 At5g51840

C2 At5g23880

C2 At5g23940

C2_At4g25720

C2 At5g51700

C2_At5g62390

C2_At3g10670(A)

2 At3g22660

2_At3g56460

2_At2g40490

C2 At3g10920

C2_At3g55800

C2_At1g54650

C2_At3g55120

C2_At2g20390

C2_At2g36740

C2 At5g04480

C2_At5g04420

C2_At5g04270

C2_At1961780

PAL1

C2 At5g27620

C2 At4g21540

C2_At4g21520

C2_At4g21445

C2_At1g29260

C2 At4g18810

C2 At2g21290

C2_At1 g49510

C2_At1 g49410

C2_At5g42700

C2_At3g19630

C2_At2g15290

C2 At2g14835

C2 At2g14910

C2 At4g33690

C2 At2g14260

C2 At3g19720

C2 At1g10240

C2 At5g49820

C2_At2g02500

C2 At4g14110

C2 At1 g64850

C2_At3g20230

C2_At5g26880

C2_At3g63490

C2 At5g52820

C2_At2g38730

C2_At3g04600

C2 At1g54460

C2_At1g54460

C2_At1g54520
F

0 C2_At3g08710

C2_At2g28380

160

C2_At3g08710

$4 \sqrt{ }$ PAL2

6

7
13
17

A 37510

13

C2 At3g51840

C2_At3g55140

2_At2g37240

C2_At2g36930

3. C2 At2g36720

9 C2 At5g06130

$30-\quad 2$ At2g35920

31 C2 At1963780

32 C2 At5g34850

32 C2_At5g06410

34 C2_At5g32450

C2_At3g03790

36 C2_At5g20350

C2_At5g20180
C2 _At2g26830

41 C2 At5g20080

$44 \quad$ C2 At4g29120

46 C2 At3g24530

C2 At4g29490

C2_At5g05920

4 C2 At2g06530

C2_At5g56940

55 C2_At5g20520

C2_At1g19140

57 C2 At2g06050

C2_At2g06005

$58 \quad$ C2_At3g43230

59 C2_At1g11440

C2 At3190

( )

C2 At2g18710

68 C2_At2g18710

C2_At2g24270

C2_At5g57970

C2_At5g58200

C2_At3g54360

C2 At3g57810

C2 At1g61620

C2 At3957280

C2 At2g28250

111 C2_At2g24390

$114 \quad$ C2_At2g24390

117 C2_At1g09760(B)

126 C2_At5g60990

127 C2_At2g26590

128 C2_At4g24820

C2_At3g11960 
amplify PAL sequences, only the same three transcriptionally active $P A L$ genes described here and in a previous study (Mahesh et al. 2006b) were amplified.

A previous study suggested that CCPALl may be involved in the differential accumulation of the main groups of CGA found in green coffee beans, the caffeoylquinic acids (Mahesh et al. 2006b). However, the quantitative gene expression results obtained in the present work using Taqman q-RT-PCR technology, while consistent with the involvement of CcPALI in CGA accumulation in coffee beans, also strongly suggest that $C C P A L 2$ and $C c P A L 3$ are likewise involved in this process. Indeed, $P A L$ gene expression analysis in various coffee tissues showed that two or three coffee $P A L$ genes are often expressed in a single tissue or organ, but not necessarily at the same stage of development. In the bean, for example, CCPAL1 and $C C P A L 3$ were found to be highly expressed at the immature stage, while the $C c P A L 2$ expression was extremely low. Yet, later in maturation (from LG stage), CCPAL1 and CCPAL3 transcript levels had fallen significantly and the CCPAL2 transcript levels had risen slightly. The high expression of $C C P A L 1$ and $C C P A L 3$ at the small green stage correlates with the high co-expression of $H Q T$ (hydroxycinnamoyl-CoA quinate hydroxycinnamoyl transferase), a gene also involved in CGA biosynthesis (Niggeweg et al. 2004). This observation suggests that the concomitant high expression of these genes leads to a high production of CGA during the SG stage (Lepelley et al. 2007). In addition, the $C c P A L s$ and $C c H Q T$ transcript levels tend to fall as the quantity of CGA drops in the later stages of bean development, suggesting that the genes are co-regulated.

The fact that all three $C c P A L$ transcripts were detected in many tissues or organs, but at quite varying levels, suggests that the corresponding enzymes probably play particular roles in different parts of the plant while simultaneously playing smaller overlapping housekeeping roles. While $C c P A L 1$ and $C c P A L 3$ appear to be more strongly linked with a high accumulation of CGA in coffee bean, it appears that $C c P A L 2$ may contribute more significantly to flavonoid accumulation. Evidence for this proposal comes from the substantial level of expression of CCPAL2 in the flower, an organ known to have relatively important rate of flavonoid synthesis. The fact that CCPAL1 transcription level was also high suggests that this gene could also contribute to the flavonoid precursor pool in this organ. Finally, it is also important to note that the three coffee $P A L$ genes are expressed when the pericarp of the coffee cherry is red, suggesting that they may participate in fruit coloration. Searching for their potential co-expression with others genes, either from the general phenylpropanoid pathway (i.e., $C 4 H$ and $4 C L$ ), or from the specific flavonoid (i.e., $C H S$ and $C H I$ ) or lignin (i.e., COMT and $C A D$ ) branches, could help to determine more precisely whether a coffee $P A L$ could be more specifically involved in one of the two major phenylpropanoid branches. Such an approach was used by Gachon et al. (2005), who showed that in Arabidopsis the paralogs of the phenylpropanoid pathway displayed a clear differential co-expression according to the culture conditions applied to the plant and its response. In the same manner, Mahroug et al. (2006) linked the specific co-expression observed for three genes (PAL, C4H and $C H S$ ) with the high flavonoid content found in the upper epidermis of $C$. roseus.

The three coffee PAL-deduced protein sequences were compared to 98 PAL protein sequences from other species. The phylogenetic tree helped to clarify that CcPAL2 was the only one of the three proteins whose sequence was branched with other PAL sequences from the Asterids, the clade to which $C$. canephora belongs. $C C P A L 2$ has been located within a coffee linkage group region that is syntenic to tomato (observation based on the results obtained by Lefebvre-Pautigny et al. 2010). This observation strongly suggests that $C C P A L 2$ and the corresponding tomato $P A L$ gene both derive from a common $P A L$ ancestor as do, most probably, the other Asterid genes whose protein-derived sequence branched together on the phylogenetic tree (Fig. 2). CCPALI and CcPAL3 could be specific Coffea paralogs produced from an ancient duplication of CCPAL2, resulting in one of the two genes being followed by a more recent duplication of the duplicated paralog, since $C c P A L 1$ and $C c P A L 3$ seem to branch very closely on the phylogenetic tree. Both $C C P A L 2$ and $C c P A L 3$ have a phase 1 intron. $C c P A L 2$ being the ancestral form, it might be assumed that $C C P A L 3$ results from the first duplication. As $C C P A L 1$ carries a phase 2 intron, it may then be alleged to be the most recent paralog, resulting from a duplication of CCPAL3. Interestingly, CcPAL1 and CcPAL3 proteins were found grouped with PtrPAL2, PtrPAL4 and PtrPAL5, three P. trichocarpa proteins encoded by genes more specifically expressed in xylem and carrying, in their promoters, five core motifs similar to elements which are known to regulate phenylpropanoid gene expression (Shi et al. 2010a, b). This result suggests that CCPAL1 and CCPAL3 may be co-expressed with genes of the phenylpropanoid pathway that lead to monolignol biosynthesis. As both paralogs seemed to be the product of duplications, lignification in woody plants could be considered as a derived function from an ancestral one from the phenylpropanoid pathway, such as flavonoid biosynthesis, the first plant protection against UV light. This observation highlights that it would be informative to isolate the $5^{\prime}$ untranslated transcribed region (UTR) and the promoter region sequences of the three $C C P A L$ paralogs to acquire meaningful additional data on their specific functions and their transcriptional control, often exercised by $R 2 R 3-M Y B$ transcription factors in monolignol and 
flavonoid synthesis (Stracke et al. 2007; Bomal et al. 2008; Luo et al. 2008).

The present work, dedicated to the family of coffee $P A L$ genes, has successfully led to identifying, characterizing and mapping three genes. Their differential expression, and particularly the association established between the high expression observed for $P A L 1, P A L 3$ and $H Q T$ genes (Fig. 3) and the high CGA accumulation in the immature coffee bean, is a preliminary step toward characterizing their functions. In further research, it would be interesting to assess if all three coffee PAL proteins are biochemically active in vitro, by producing them in Escherichia coli, and then testing their ability to catalyze the deamination of L-phenylalanine to form trans-cinnamic acid (Reichert et al. 2009). As a key step, studying coffee $P A L$ expression profiles and segregation in different $C$. canephora varieties and in their offspring after crossing, and quantifying the related phenylpropanoid levels for association studies, will be particularly useful for advancing coffee breeding programs. The use of such genetic markers encoding proteins associated with flavonoids and CGA accumulation could carry substantial interest for the selection of $C$. canephora varieties with improved traits, e.g., varieties rich in antioxidant compounds beneficial to human health or with improved organoleptic quality.

Acknowledgments We wish to thank Victoria Caillet for generating the RNA/cDNA samples used in the q-RT-PCR experiments, Charlène Perrois for part of the q-RT-PCR analysis and Gérald Cheminade for participating in the design and efficiency test of the Taqman primers/probes set. We acknowledge Dr. Ir Zaenudin, Dr. Surip Mawardi and Priyono of the Indonesian Coffee and Cacao Research Institute (ICCRI) for supplying the BP409 C. canephora (robusta) samples used here from the ICCRI collection. We thank Mr. Francis Richard for looking after the coffee plants in the IRD greenhouses. We are also particularly grateful to Isabelle Privat for her unceasing, stimulating scientific input and advice, and to Pierre Broun for his support.

Open Access This article is distributed under the terms of the Creative Commons Attribution License which permits any use, distribution, and reproduction in any medium, provided the original author(s) and the source are credited.

\section{References}

Abdulrazzak N, Pollet B, Ehlting J, Larsen K, Asnaghi C, Ronseau S, Proux C, Erhardt M, Seltzer V, Renou JP, Ullmann P, Pauly M, Lapierre C, Werk-Reichhart D (2006) A coumaroyl-ester3-hydroxylase insertion mutant reveals the existence of nonredundant meta-hydroxylation pathways and essential roles for phenolic precursors in cell expansion and plant growth. Plant Physiol 140:30-48

Bazzano LA, He J, Ogden LG, Loria CM, Vupputuri S, Myers L, Whelton PK (2002) Fruit and vegetable intake and risk of cardiovascular disease in US adults: the first National Health and Nutrition Examination Survey Epidemiologic Follow-up Study. Am J Clin Nutr 76:93-99

Bertrand C, Noirot M, Doulbeau S, de Kochko A, Hamon S, Campa C (2003) Chlorogenic acid content swap during fruit maturation in Coffea pseudozanguebariae. Qualitative comparison with leaves. Plant Sci 165:1355-1361

Besseau S, Hoffman L, Geoffroy P, Lapierre C, Pollet B, Legrand M (2007) Flavonoid accumulation in Arabidopsis repressed in lignin synthesis affects auxin transport and plant growth. Plant Cell 19:148-162

Bomal C, Bedon F, Caron S, Mansfiled SD, Levasseur C, Cooke JE, Blais S, Tremblay L, Morency MJ, Pavy N, Grima-Pettenati J, Séguin A, Mackay J (2008) Involvement of Pinus taeda MYB1 and $M Y B 8$ in phenylpropanoid metabolism and secondary cell wall biogenesis: a comparative in planta analysis. J Exp Bot 59:3925-3939

Breathnach R, Chambon P (1981) Organization and expression of eukaryotic split genes coding for proteins. Annu Rev Biochem 50:349-383

Campa C, Noirot M, Bourgeois M, Pervent M, Ky CL, Chrestin H, Hamon S, de Kochko A (2003) Genetic mapping of a caffeoylcoenzyme A 3-O-methyltransferase gene in coffee trees. Impact on chlorogenic acid content. Theor Appl Genet 107:751-756

Chang A, Lim MH, Lee SW, Robb EJ, Nazar RN (2008) Tomato phenylalanine ammonia-lyase gene family, highly redundant but strongly underutilized. J Biol Chem 283:33591-33601

Clé C, Hill LM, Niggeweg R, Martin CR, Guissez CR, Prinsen E, Jansen MA (2008) Modulation of chlorogenic acid biosynthesis in Solanum lycopersicum; consequences for phenolic accumulation and UV-tolerance. Phytochemistry 69:2149-2156

Clifford MN (2000) Chlorogenic acids and other cinnamates-nature, occurrence, dietary burden, absorption and metabolism. J Sci Food Agric 80:1033-1043

Clifford MN (2004) Diet-derived phenols in plasma and tissues and their implications for health. Planta Med 70:1103-1114

Clifford MN, Knight S, Surucu B, Kuhnert N (2006) Characterization by $\mathrm{LC}^{-M S^{\mathrm{n}}}$ of four new classes of chlorogenic acids in green coffee beans: dimethoxycinnamoylquinic acids, diferuloylquinic acids, caffeoyl-dimethoxycinnamoylquinic acids, and feruloyldimethoxycinnamoylquinic acids. J Agric Food Chem 54:1957-1969

Cochrane FC, Davin LB, Lewis NG (2004) The Arabidopsis phenylalanine ammonia lyase gene family: kinetic characterization of the four PAL isoforms. Phytochemistry 65:1557-1564

Cos P, De Bruyne T, Hermans N, Apers S, Berghe DV, Vlietinck AJ (2005) Proanthocyanidins in health care: current and new trends. Curr Med Chem 11:1345-1359

Cramer CL, Edwards K, Dron M, Liang X, Dildine SL, Bolwell GP, Dixon RA, Lamb CJ, Schuch W (1989) Phenylalanine ammonialyase gene organization and structure. Plant Mol Biol $12: 367-383$

Cuevas-Rodriguez EO, Dia VP, Yousef GG, Garcia-Saucedo PA, Lopez-Medina J, Paredes-Lopez O, Gonzalez De Mejia A, Lila MA (2010) Inhibition of pro-inflammatory responses and antioxidant capacity of Mexican blackberry (Rubus spp.) extracts. J Agric Food Chem 58:9542-9548

Dixon R, Paiva N (1995) Stress-induced phenylpropanoid metabolism. Plant Cell 7:1085-1097

Drummond AJ, Ashton B, Buxton S, Cheung M, Cooper A, Duran C, Field M, Heled J, Kearse M, Markowitz S, Moir R, Stones-Havas S, Sturrock S, Thierer T, Wilson A (2011) Geneious v5.5 software, available from http://www.geneious.com

Fedorov A, Suboch G, Bujakov M, Fedorova L (1992) Analysis of nonuniformity in intron phase distribution. Nucleic Acids Res 20:2553-2557 
Fukasawa-Akada T, Kung SD, Watsin JC (1996) Phenylalanine ammonia-lyase gene structure, expression, and evolution in Nicotiana. Plant Mol Biol 30:711-722

Gachon CM, Langlois-Meurinne M, Henry Y, Saindrenan P (2005) Transcriptional co-regulation of secondary metabolism enzymes in Arabidopsis: functional and evolutionary implications. Plant Mol Biol 58:229-245

Go M, Wu X, Liu X (2005) Chalcones: an update on cytotoxic and chemoprotective properties. Curr Med Chem 12:481-499

Hahlbrock K, Grisebach H (1979) Enzymatic controls in biosynthesis of lignin and flavonoids. Annu Rev Plant Physiol 30:105-130

Han H, Baik BK (2008) Antioxidant activity and phenolic content of lentils (Lens culinaris), chickpeas (Cicer arietinum L.), peas (Pisum sativum L.) and soybeans (Glycine max), and their quantitative changes during processing. Int J Food Sci Technol 43:1971-1978

Hoffmann L, Besseau S, Geoffroy P, Ritzenthaler C, Meyer D, Lapierre C, Pollet B, Legrand M (2004) Silencing of hydroxycinnamoyl-coenzyme A shikimate/quinate hydroxycinnamoyltransferase affects phenylpropanoid biosynthesis. Plant Cell 16:1446-1465

Huang J, Gu M, Lai Z, Fan B, Shi K, Zhou YH, Yu JQ, Chen Z (2010) Functional analysis of the Arabidopsis $P A L$ gene family in plant growth, development, and response to environmental stress. Plant Physiol 153:1526-1538

Joët T, Laffargue A, Salmona J, Doulbeau S, Descroix F, Bertrand B, de Kochko A, Dussert S (2009) Metabolic pathways in tropical dicotyledonous albuminous seeds: Coffea arabica as a case study. New Phytol 182:146-162

Joos HJ, Hahlbrock K (1992) Phenylalanine ammonia lyase in potato (Solanum tuberosum L.). Genomic complexity, structural comparison of two selected clones and modes of expression. Eur $\mathbf{J}$ Biochem 204:621-629

Kao YY, Harding SA, Tsai CJ (2002) Differential expression of two distinct phenylalanine ammonia-lyase genes in condensed tannin-accumulating and lignifying cells of quaking aspen. Plant Physiol 130:796-807

Koshiro Y, Jackson MC, Katahira R, Wang ML, Nagai C, Ashihara H (2007) Biosynthesis of chlorogenic acids in growing and ripening fruits of Coffea arabica and Coffea canephora plants. Z Naturforsch 62:731-742

Ky CL, Louarn J, Guyot B, Charrier A, Hamon S, Noirot M (1999) Relations between and inheritance of chlorogenic acid contents in an interspecific cross between Coffea pseudozanguebariae and Coffea liberica var 'dewevrei'. Theor Appl Genet 98:628-637

Ky CL, Louarn J, Dussert S, Guyot B, Hamon S, Noirot M (2001) Caffeine, trigonelline, chlorogenic acids and sucrose diversity in wild Coffea arabica L. and Coffea canephora P. accessions. Food Chem 75:223-230

Lefebvre-Pautigny F, Wu F, Philippot M, Rigoreau M, Priyono P, Zouine M, Frasse P, Bouzayen M, Broun P, Pétiard V, Tanksley SD, Crouzillat D (2010) High resolution synteny maps allowing direct comparisons between the coffee and tomato genomes. Tree Genet Genomes 6:565-577

Lepelley M, Cheminade G, Tremillon N, Simkin A, Caillet V, McCarthy J (2007) Chlorogenic acid synthesis in coffee: An analysis of CGA content and real-time RT-PCR expression of HCT, HQT, C3H1, and CCoAOMT1 genes during grain development in C. canephora. Plant Sci 172:978-996

Lila MA (2007) From beans to berries and beyond. Teamwork between plant chemicals for protection of optimal human health. In: Healthy aging and longevity: Third International Conference. Ann NY Acad Sci, vol 1114. Blackwell, Boston, pp 372-380

Lin C, Mueller LA, Mc Carthy J, Crouzillat D, Pétiard V, Tanksley SD (2005) Coffee and tomato share common gene repertoires as revealed by deep sequencing of seed and cherry transcripts. Theor Appl Genet 112:114-130

Luo J, Butelli E, Hill L, Parr A, Niggeweg R, Bailey P, Weisshaar B, Martin C (2008) AtMYB12 regulates caffeoyl quinic acid and flavonol synthesis in tomato: expression in fruit results in very high levels of both types of polyphenol. Plant J 56:316-326

Mahesh V, Million-Rousseau R, Ullmann P, Chabrillange N, Mondolot L, Noirot M, Hamon S, de Kochko A, Werck-Reihhart D, Campa C (2006a) Functional identification of two CYP98A genes involved in coffee tree caffeoyl ester biosynthesis. 21ème Colloque Scientifique International sur le Café ASIC (Association Scientifique Internationale sur le café) (Montpellier, France)

Mahesh V, Rakotomalala J, Le Gal L, Vigne H, de Kochko A, Hamon S, Noirot M, Campa C (2006b) Isolation and genetic mapping of a Coffea canephora phenylalanine ammonia-lyase gene $(C C P A L 1)$ and its involvement in the accumulation of caffeoyl quinic acids. Plant Cell Rep 25:986-992

Mahroug S, Courdavault V, Thiersault M, St-Pierre B, Burlat V (2006) Epidermis is a pivotal site of at least four secondary metabolic pathways in Catharanthus roseus aerial organs. Planta 223:1191-1200

Mohan SM, Madhusudhana R, Mathur K, Chakravarthi DVN, Rathore S, Reddy RN, Satish K, Srinivas G, Mani NS, Seetharama N (2010) Identification of quantitative trait loci associated with resistance to foliar diseases in sorghum [Sorghum bicolor (L.) Moench]. Euphytica 176:199-211

Niggeweg R, Michael AJ, Martin C (2004) Engineering plants with increased levels of the antioxidant chlorogenic acid. Nat Biotechnol 22:746-754

Olsen KM, Lea US, Slimestad R, Verheul M, Lillo C (2008) Differential expression of four Arabidopsis PAL genes; PAL1 and $P A L 2$ have functional specialization in abiotic environmental-triggered flavonoid synthesis. J Plant Physiol 165:1491-1499

Osakabe Y, Osakabe K, Kawai S, Katayama Y, Morohoshi N (1995) Characterization of the structure and determination of mRNA levels of the phenylalanine ammonia-lyase gene family from Populus kitakamiensis. Plant Mol Biol 28:1133-1141

Poncet V, Rondeau M, Tranchant C, Cayrel A, Hamon S, de Kochko A, Hamon P (2006) SSR mining in coffee tree EST databases: potential use of EST-SSRs as markers for the Coffea genus. Mol Genet Genomics 276:436-449

Privat I, Foucrier S, Prins A, Epalle T, Eychenne M, Kandalaft L, Caillet V, Lin C, Tanksley S, Foyer C, McCarthy J (2008) Differential regulation of grain sucrose accumulation and metabolism in Coffea arabica (Arabica) and Coffea canephora (Robusta) revealed through gene expression and enzyme activity analysis. New Phytol 178:781-797

Raes J, Rohde A, Christensen JH, Van de Peer Y, Boerjan W (2003) Genome-wide characterization of the lignification toolbox in Arabidopsis. Plant Physiol 133:1051-1071

Rasmussen S, Dixon A (1999) Transgene-mediated and elicitorinduced perturbation of metabolic channeling at the entry point into the phenylpropanoid pathway. Plant Cell 11:1537-1552

Reichert AI, He X-Z, Dixon RA (2009) Phenylalanine ammonia-lyase (PAL) from tobacco (Nicotiana tabacum): characterization of the four tobacco $P A L$ genes and active heterotetrameric enzymes. Biochem J 424:233-242

Reimers PJ, Leach JE (1991) Race-specific resistance to Xanthomonas oryzae pv. oryzae conferred by bacterial blight resistance gene Xa-10 in rice Oryzae sativa involves accumulation of a lignin-like substance in host tissues. Physiol Mol Plant Pathol 38:39-55

Rogers WJ, Bezard G, Deshayes A, Meyer I, Petiard P, Marraccini P (1999) Biochemical and molecular characterization and 
expression of the 11S-type storage protein from Coffea arabica endosperm. Plant Physiol Biochem 37:261-272

Rohde A, Morreel K, Ralph J, Goeminne G, Hostyn V, De Rycke R, Kushnir S, Van Doorsselaere J, Joseleau JP, Vuylsteke M, Van Driessche G, Van Beeumen J, Messens E, Boerjan W (2004) Molecular phenotyping of the pal1 and pal2 mutants of Arabidopsis thaliana reveals far-reaching consequences on and carbohydrate metabolism. Plant Cell 16:2749-2771

Sawa T, Nakao M, Akaike T, Ono K, Maeda H (1999) Alkylperoxyl radical-scavenging activity of various flavonoids and other phenolic compounds: implications for the anti-tumor-promoter effect of vegetables. J Agric Food Chem 47:397-402

Schovankova J, Opatova H (2011) Changes in phenols composition and activity of phenylalanine-ammonia lyase in apples after fungal infection. Hort Sci 38:1-10

Schuster B, Rétey J (1994) Serine-202 is the putative precursor of the active site dehydroalanine of phenylalanine ammonia lyase. Sitedirected mutagenesis studies on the enzyme from parsley (Petroselinum crispum L.). FEBS Lett 349:252-254

Shi R, Sun Y-H, Li Q, Heber S, Sederoff R, Chiang VL (2010a) Towards a systems approach for lignin biosynthesis in Populus trichocarpa: transcript abundance and specificity of the monolignol biosynthetic genes. Plant Cell Physiol 51:144-163

Shi R, Yang C, Lu S, Sederoff R, Chiang VL (2010b) Specific downregulation of $P A L$ genes by artificial microRNAs in Populus trichocarpa. Planta 232:1281-1288

Simkin AJ, Qian T, Caillet V, Michoux F, Ben Amor M, Lin C, Tanksley S, McCarthy J (2006) Oleosin gene family of Coffea canephora: quantitative expression analysis of five oleosin genes in developing and germinating coffee grain. J Plant Physiol 163:691-708

Srinivas G, Satish K, Madhusudhana R, Reddy RN, Mohan SM, Seetharama N (2009) Identification of quantitative trait loci for agronomically important traits and their association with genicmicrosatellite markers in sorghum. Theor Appl Genet 118:1439-1454

Stracke R, Ishihara H, Huep G, Barsch A, Mehrtens F, Niehaus K, Weisshaar B (2007) Differential regulation of closely related R2R3-MYB transcription factors controls flavonol accumulation in different parts of the Arabidopsis thaliana seedling. Plant $\mathrm{J}$ 50:660-677
Subramaniam R, Reinold S, Molitor EK, Douglas CJ (1993) Structure, inheritance, and expression of hybrid poplar (Populus trichocarpa $\times$ Populus deltoides) phenylalanine ammonia-lyase genes. Plant Physiol 102:71-83

Tamagnone L, Merida A, Stacey N, Plaskitt K, Parr A, Chang CF, Lynn D, Dow JM, Roberts K, Martin C (1998) Inhibition of phenolic acid metabolism results in precocious cell death and altered cell morphology in leaves of transgenic tobacco plants. Plant Cell 10:1801-1816

Tovar MJ, Romero MP, Girona J, Motilva MJ (2002) L-phenylalanine ammonia-lyase activity and concentration of phenolics in developing olive (Olea europaea L cv Arbequina) fruit grown under different irrigation regimes. J Sci Food Agri 82:892-898

Tuskan GA, DiFazio S, Jansson S, Bohlmann J, Grigoriev I, Hellsten U, Putnam N, Ralph S, Rombauts S, Salamov A et al (2006) The genome of black cottonwood, Populus trichocarpa (Torr. \& Gray). Science 313:1596-1604

Vallverdu-Queralt A, Medina-Remon A, Andres-Lacueva C, Lamuela-Raventos RM (2011) Changes in phenolic profile and antioxidant activity during production of diced tomatoes. Food Chem 126:1700-1707

Ververidis F, Trantas E, Douglas C, Vollmer G, Kretzschmar G, Panopoulos N (2007) Biotechnology of flavonoids and other phenylpropanoid-derived natural products. Biotechnol J 10:1214-1234

Vogt T (2010) Phenylpropanoid biosynthesis. Mol Plant 3:2-20

Wanner LA, Li G, Ware G, Somssich IE, Davis KR (1995) The phenylalanine ammonia-lyase gene family in Arabidopsis thaliana. Plant Mol Biol 27:327-338

Winkel-Shirley B (2002) Biosynthesis of flavonoids and effects of stress. Curr Opin Plant Biol 5:218-223

Wu F, Eannetta NT, Xu Y, Tanksley SD (2009) A detailed synteny map of the eggplant genome based on conserved ortholog set II (COSII) markers. Theor Appl Genet 118:927-935

Yamada T, Tanaka Y, Sriprasertsak P, Kato H, Hashimoto T, Kawamata S, Ichinose Y, Kato H, Shiraishi T, Oku H (1992) Phenylalanine ammonia-lyase genes from Pisum sativum: structure, organ-specific expression and regulation by fungal elicitor and suppressor. Plant Cell Physiol 33:715-725

Yen WJ, Wang BS, Chang LW, Duh PD (2005) Antioxidant properties of roasted coffee residues. J Agric Food Chem 53:2658-2663 